\title{
Analysis and diagnosis for the conservation and architectural reuse of the old barn and horse stables of the Chapingo Autonomous University
}

\author{
F. J. Soria López, F. H. Alfaro Salazar \& A. B. García Koch \\ Academic and Research Faculty on Conservation and \\ Reuse of Built Heritage, Universidad Autónoma Metropolitana, \\ Xochimilco in México City, México
}

\begin{abstract}
This reuse project is based on the importance and value of built heritage conservation as well as the usefulness of obsolete infrastructure as is the case with the old cow barn and horse stables of the Chapingo Autonomous University $(\mathrm{UACH})$ - the main school of agriculture in Mexico founded in 1854. This plan seeks to continue and consolidate the recovery process of historical buildings of this public university which began more than a decade ago with the intervention in the Main House of the hacienda, the rescuing of the old library, known as the "Parthenon" and, of course, the recovery of the old pig barn, all of the former with new institutional uses. The project basically includes three phases. The first, dedicated to the surveys and recollection of historical data, photographs and general information needed to document the evolution and changes these two buildings have experienced over time. The second stage of analysis was engaged in determining the state of conservation of both structures and their possibilities of reuse. The third and last part of the project included a series of recommendations and the development of an architectural reuse proposal for the horse stable and cow barn, as well as the regeneration of the surrounding open spaces in this area of the campus, safeguarding their characteristics and heritage values and simultaneously generating a modern and functional space for the university's new General and Historic Archives headquarters.

Keywords: adaptive reuse, heritage architecture conservation, architectural reutilization, architectural integration, heritage value.
\end{abstract}




\section{Introduction}

The proposal to rescue the buildings of the old horse stable and cow barn of the former National College of Agriculture (ENA), moved to the Chapingo hacienda shortly after de Mexican revolution, poses the recovery of the first specialized facilities built in this farm, when it was adapted as an agricultural school back in 1924. Due to their importance and significance for the institutions' history and their regard as part of its built heritage, both structures were considered to be preserved and reused in the Urban Master Plan for the Reorganization and Proper Reuse of the Chapingo Campus [1] developed in 2008.

These buildings ceased to operate many years ago for their original purposes, when they became obsolete towards the 1970s, undergoing major transformations, as well as their surrounding environment, to adapt them to new and changing spatial and technological needs of the UACH. In this way, the stables and barn were recycled for maintenance activities and are currently used as electricity, masonry and carpentry workshops. Given the conditions mentioned above, even though they are recognized as significant places of the campus, with a very important heritage value, nowadays both buildings have a great physical, functional and environmental deterioration which puts at risk their conservation in the short run as well as their permanence in the near future.

There is not too much background information regarding the construction of these buildings; however, it is sure to say that their installation took place towards the end of the 1920s. In a photograph of an original blueprint of the horse stables the date on the document, although somewhat blurred, points towards 1926 or 1928, which coincides with the initial period of adapting the ENA in Chapingo. The barn (and even the pig house nearby) has the same building configuration as those of the stables in terms of materials and building systems for walls and roofs, which confirms their construction around the same time period.

The main idea at that time was to provide the ENA with an updated infrastructure for teaching in the breeding and care of animals. In this sense the structures were not only built from imported models adapted to the Mexican context, they were developed with the most modern technology for the proper functioning of barns and stables: mechanical load belts for food, steal ventilation ducts, extraction ducts to pass food, mechanical chain carriers, concrete floors, steel pipes, among others. Many photographs found (most not dated), taken from the outside of the buildings, give a good view of the general architectural settings. The images make it clear, above all, the great transformation that the former open spaces have suffered over the years (see figures 1 and 2); from a scheme of isolated constructions that had an important proportion of open outer space for animals it became, 85 years later, in a chaotic ensemble, tremendously invaded by a great number of uncontrolled small buildings and sheds, poorly designed, made with low-quality materials and without any criterion of urban and architectural integration. 


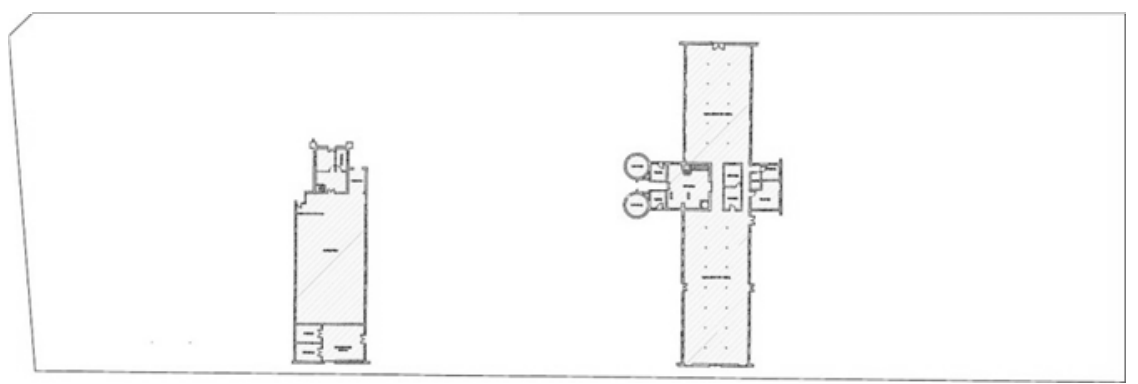

Figure 1: 1926-1930: construction of the ENA livestock facilities, consisting of a series of buildings dedicated to horse stables, cow barns, chicken coops and pig barns (in the drawing are the first two).

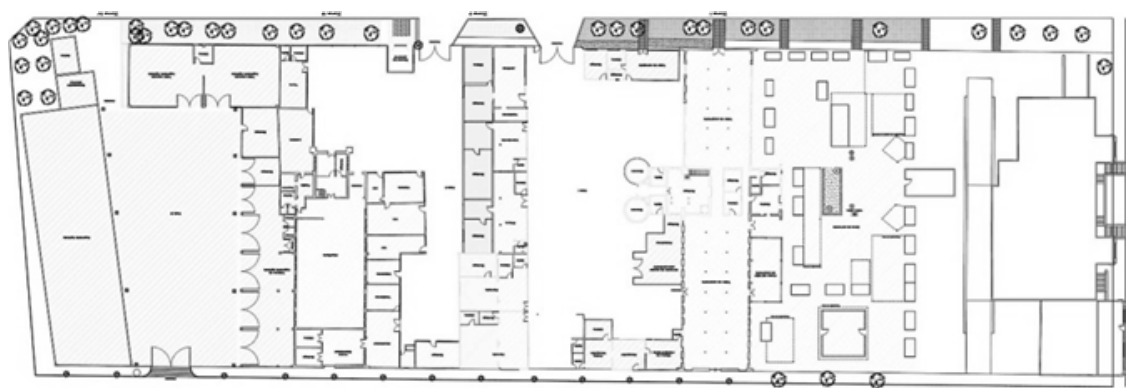

Figure 2: 2000-2010: the drawing records the current situation, with the changes and transformations of the settings since the end of the 1920s until 2010. The chaotic scheme is evident.

\section{Architectural description}

The location of livestock facilities in the South-West side of the property was probably due, at that time, to the fact that it was a relatively "far away" zone from the main house and other teaching facilities of the ENA. The farthest building (to the South-West) was the pig barn; then came the horse stable and finally the cow barn.

The general layout of the buildings has a rectangular scheme, using a northsouth orientation in its longitudinal axis, while the transverse axis has an eastwest direction. Both buildings have the same alignment in their south facades, situation which does not happen on the north facades, because the cow barn is much longer than the horse stables. Between the two, there was a generous open space, of square proportions, approximately $50 \mathrm{~m}$. long on each side, once fenced, for the handling of animals on the outside. Currently this former 'patio' has disappeared, since the space has been occupied by a series of sheds and small constructions with no order or architectural quality at all. 
The horse stable is a fairly simple building. Its plan has two well defined and distinct parts: the first, occupies a rectangular plan, on the ground floor, without intermediate supports, generating an ample space of $12 \times 24 \mathrm{~m}$. On the north side the building has three volumes; in the center a two stories high construction of rectangular proportions ( 6 x $8 \mathrm{~m}$.); on each side of the former a small square room $3 \times 3 \mathrm{~m}$. The bigger space housed the horses, while the northern body served as access control, storage on the second floor and the two adjacent rooms for the staff.
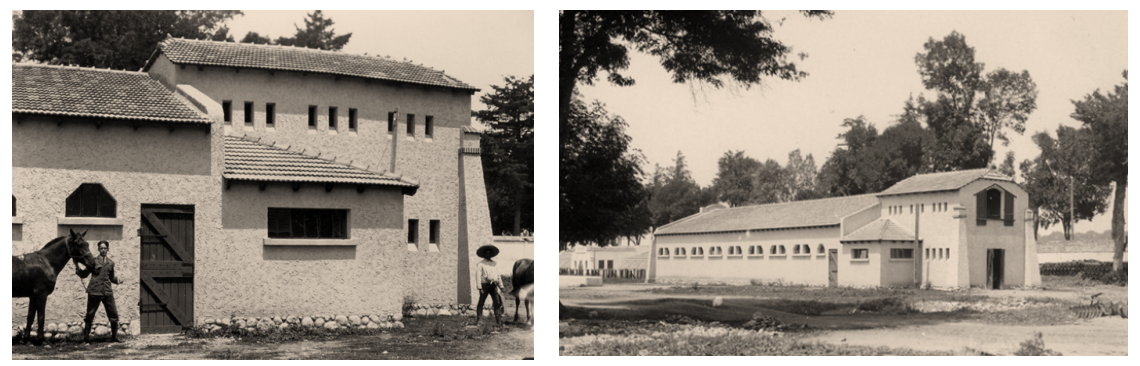

Figure 3: $\quad$ Two images of the horse stables in the 1930s.

The roof tops are pitched, at different levels, in accordance to the spaces they cover. It is important to mention that the structural solution used for the roof is with steel trusses with I beams and wood slats to support the cement roof tiles as a final cladding.

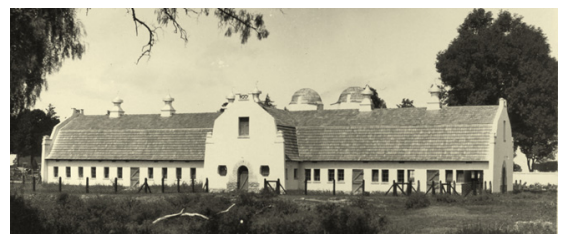

(a)

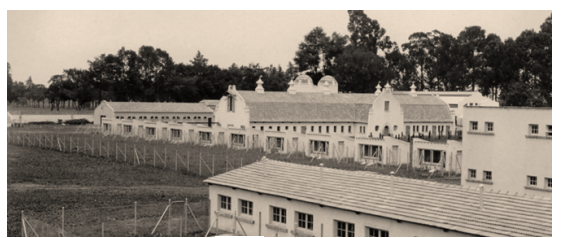

(b)

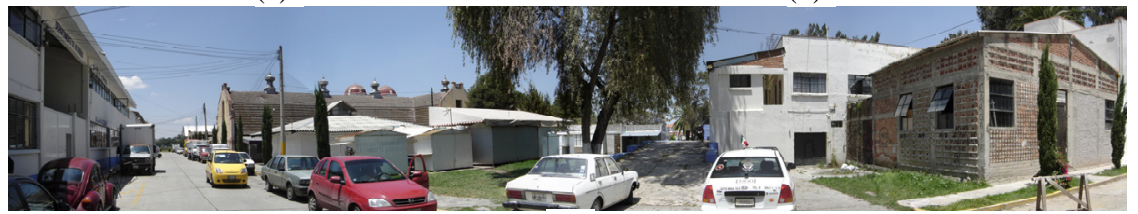

(c)

Figure 4: Above, two old images of the livestock facilities; (a) the cow barn seen from the east; (b) a general view of the area; (c) a recent view of the same area seen from the east.

On the other hand, the building that houses the cow barn has a more elaborate design if compared to the horse stables. It is a construction with a rectangular, very long $(15 \times 50 \mathrm{~m})$ floor plan, two stories high, with a smaller rectangular plan, perpendicular to de former, slightly off the center (which breaks the 
symmetry of the building), that forms a cross plan, dividing the barn in two wings, one slightly longer than the other. On the west façade, two big round silos three stories high dominate the composition.

The construction of the cow barn in Chapingo, apparently takes the design principles developed in the United States at the beginning of the 20th century for Dairy Barns, in order to improve the conditions of hygiene and production of such facilities. The basic components were as follows:

- Building of two floors: the ground floor housed the cattle with centralized access and hallway, with steel stanchions to separate animals in individual spaces and the use of the concrete floors. The top floor, of larger dimensions was used to store hay and pasture.

- Well ventilated spaces, through windows on the ground floor and galvanized steel ducts with roof outlets on the top floor.

- The use of gambrel roofs, which made an ample hayloft and could be erected with pre-fabricated trusses. The use of the shawver type truss allowed a self-standing structure that made building easier.

- Incorporation of mechanized technology for easy loading, transportation and food storage.

- The construction of vertical silos at the side of the barn, allowing storage of more fresh pasture for the winter season.

- It was recommended that the milk house be nearby but separate from the stables.

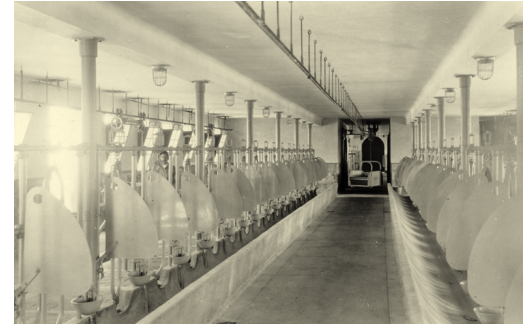

(a)

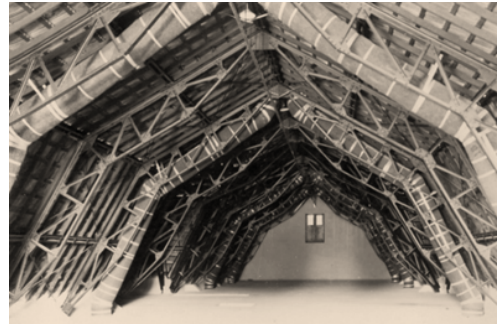

(b)

Figure 5: Indoor photographs of the cow barn; (a) the ground floor with individual stanchions; (b) the ample hayloft atop.

The following description may well apply in general to Chapingo's barn:

Agricultural college experiment stations promoted the gambrel-roofed, ground stable barn design, which was widely adopted throughout the country. These barns housed cows on a washable concrete floor in steel pipe stanchions at ground level. The gambrel roof made an ample hayloft and could be erected with pre-fabricated trusses. Ducts from steel ventilators atop the roof provided fresh air for the cows, and long rows of small windows gave light to the stable area [2].

The cow barn has two levels; the ground floor for livestock in the north and south wings; in the central spaces, service and control rooms, in addition to the 
stairs that lead to the upper floor. On the second level a generous space of ample proportions for storage. On the outside, with only one level, but tall and slender, two silos for food and grain storage. The original design envisaged three main facades, on the north and south sides which close the main rectangular nave, and one to the east on the smaller perpendicular volume that defines the cross plan. The three are composed of a small stone plinth on the base, brick door and window frames, brick walls covered with lime mortar, painted and crowned with brick tiles on the top perimeter.

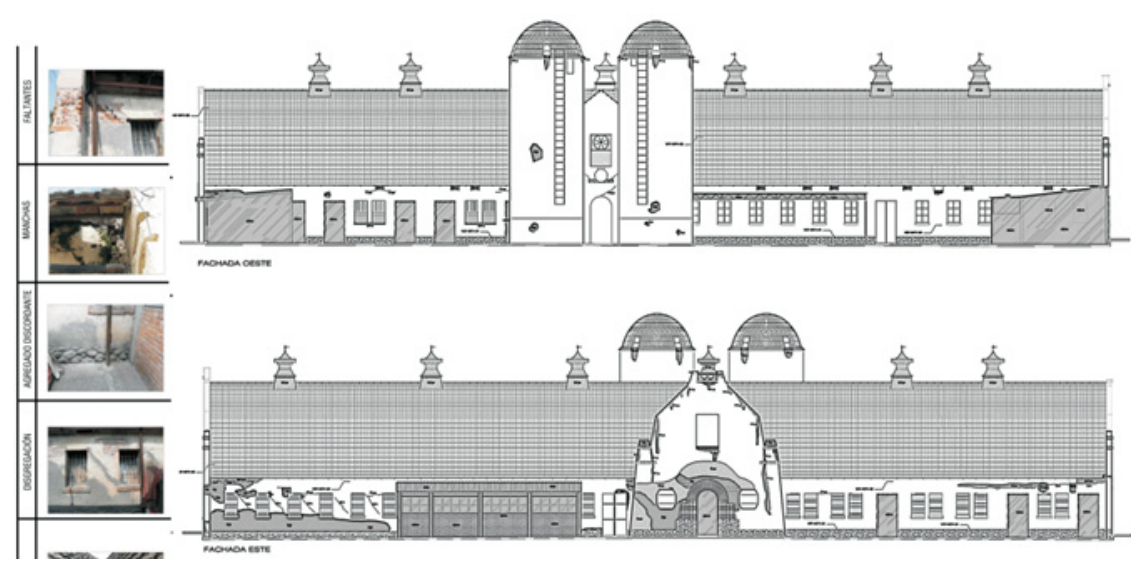

Figure 6: Drawing of the facades of the barn with precise documentation of the main damage and deteriorations they currently have.

\section{Significance assessment}

What makes the old horse stables and cow barn valuable? Of course it has to do with their long presence in the urban settings of the Chapingo campus, since this extraordinary hacienda was reused as the ENA. However, in a more detailed analysis and relating all the prior information we can describe more precisely the importance that this architectural heritage represents for the university.

In the first place we must point out their importance as historical documents and of course their symbolic character for the institution. Furthermore, despite the fact that both buildings have an advanced state of deterioration and have been transformed in different moments of their existence, they still maintain the spatial, material and compositional characteristics of the utilitarian architecture of the 1920s used in these kind of facilities (probably unique in all Mexico). The vast majority of the data and authentic values are there: building system, architectural finishes, original windows and doors, blacksmith parts, ventilation ducts, mechanical devices, among others. They were modern facilities for the time, dedicated to the teaching and professionalization for livestock activities.

The architectural composition of the stable and barn is relatively simple and sober, reflecting their functional nature. While it is true that it is a modest architecture, the recovery of both buildings and the immediate open spaces, at 
the moment completely invaded, will reestablish the environmental properties and enhance the perception of the urban settings. The cow barn is a much more elaborated building and has a significant presence on the campus. Its practical character was no excuse to incorporate important decorative elements of that time, most of neo-colonial style influence: exposed brick, 'talavera' tile, brick vaults. At the same time this building has a clear influence of Anglo-Saxon tradition that was integrated in the campus with the architectural language of that time.

\section{The reuse project}

Before restoring a historic barn or rehabilitating it for a new use, an owner should study the building thoroughly. This process involves finding out when the barn was built, who built it, and why. It means understanding how the building was changed through the years. It means assessing the condition of the barn, and understanding its components. This process has as its end an appreciation of the building's historic character, that is, the sense of time and place associated with it. It is this physical presence of the past that gives historic buildings their significance [3].

The UACH has been working through the University Archives Committee, in order to establish new institutional policies that allow us to retrieve, collect, process, systematize and store all bibliographic and documentary material (content in different media) of the university. The substantive argument that supports the idea of having a University Archives (AU) in form and substance is nourished by different considerations:

- To establish a place for all the University's files, as the location that will enable to preserve the schools memory, nourish its identity and enhance its personality (since the founding of the ENA on February 22, 1854).

- Integrate in a structured way the General Archives, the Historical Archive and all Academic Departments' files.

- $\quad$ Organize the natural structure for all the institutional files

- To comply with the requirements of the Law of Transparency and Access to Information.

The institution requires a space to host this important function and it was considered appropriate to locate it in one of their most emblematic buildings. The idea is twofold: safeguarding of the most representative architectural heritage buildings of the UACH and at the same time recover, conserve and systematize all the University's historical and current file information. It seems that the old barn and stables are ideal places for this.

The project contemplates, as a first approach, to recover the invaded outdoor spaces and involves the demolition of buildings and facilities attached two both heritage constructions. The installations of additional services for the new use include gardens, squares, rest areas, as well as a cafeteria for users and visitors. 


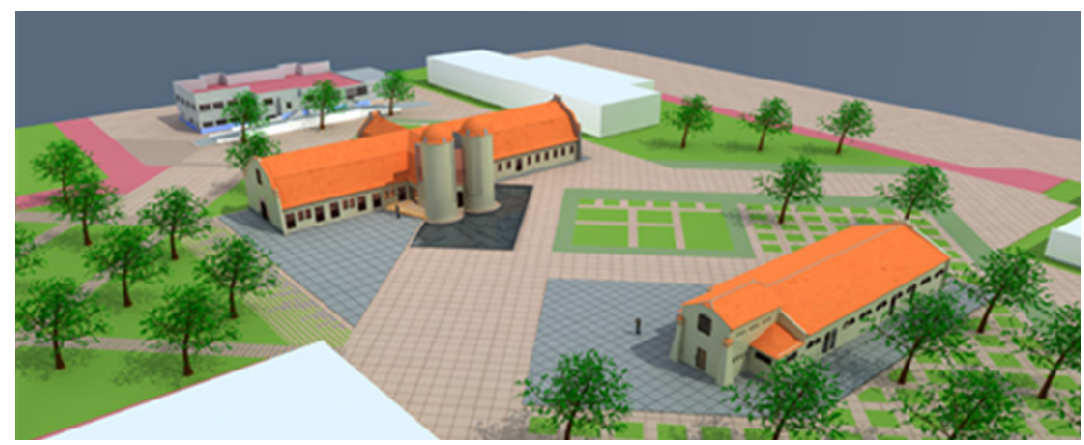

(a)

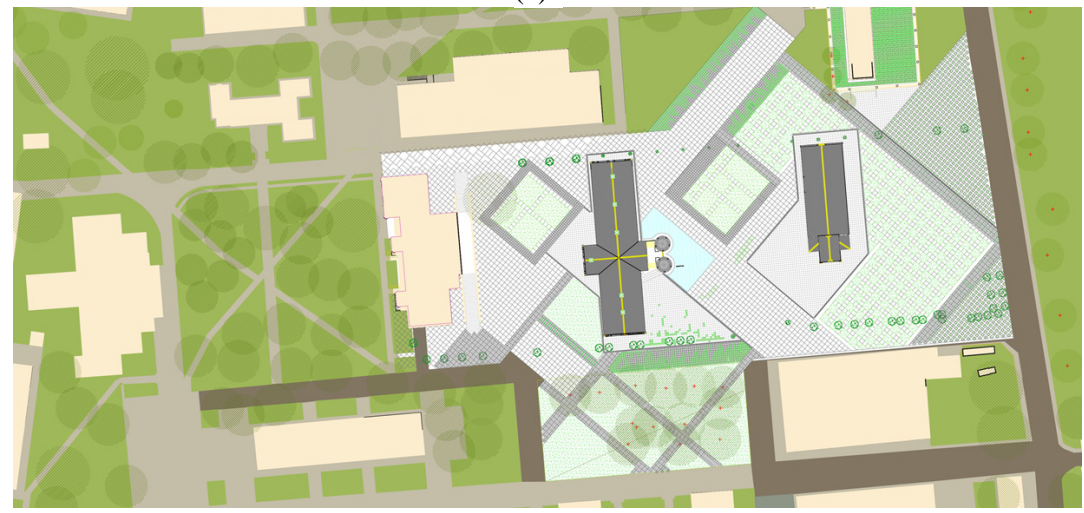

(b)

Figure 7: (a) A view of both buildings with recovered open spaces; (b) the general plan of the urban settings.

The program is distributed in both buildings; the former barn will host the inner workings spaces of the archives, while the horse stables will be used as a more flexible space aimed towards academic and cultural dissemination activities as exhibitions, seminars or workshops. The criteria and design intentions in both buildings can be summarized as follows:

- In the first place, the cow barn will become the main headquarters of the UACH Archives, where all administrative, technical, file storage and care activities will be carried out. This property has two distinct levels: the ground level where cattle were kept, which has the more 'functional' spaces, with good ventilation and natural lighting virtually in the entire perimeter. The top floor, on the other hand, was a less 'dynamic' space, and was designed to store food and hay, was dark, dry, poorly ventilated and with a restricted access. Taking advantage of these features the proposal recovers the vocation of the existing spaces, incorporating on the ground floor the more "active" part of the Archives, that is, reception, classification, repairing, registration, restoration, reproduction, attention to users, as well as 
offices of managers and support staff. The upper level will be used to accommodate the main files in special mobile compactor shelving cabinets, and also includes a consultation room.

- The layout takes advantage of the original plan which is a very long rectangle (50 x $12 \mathrm{~m}$. approximately) divided in two non-symmetrical wings by a perpendicular body, smaller than the former, generating a cross plan building. The smaller central body was used to contain the main entrance, vertical circulations and elevator, as well as reception and restrooms services. The bigger South side wing will have the main operational services of the archive, i.e. reception, classification, registration, reproduction and a first file space on ground floor. The smaller North wing will accommodate the offices, as well as general staff areas.

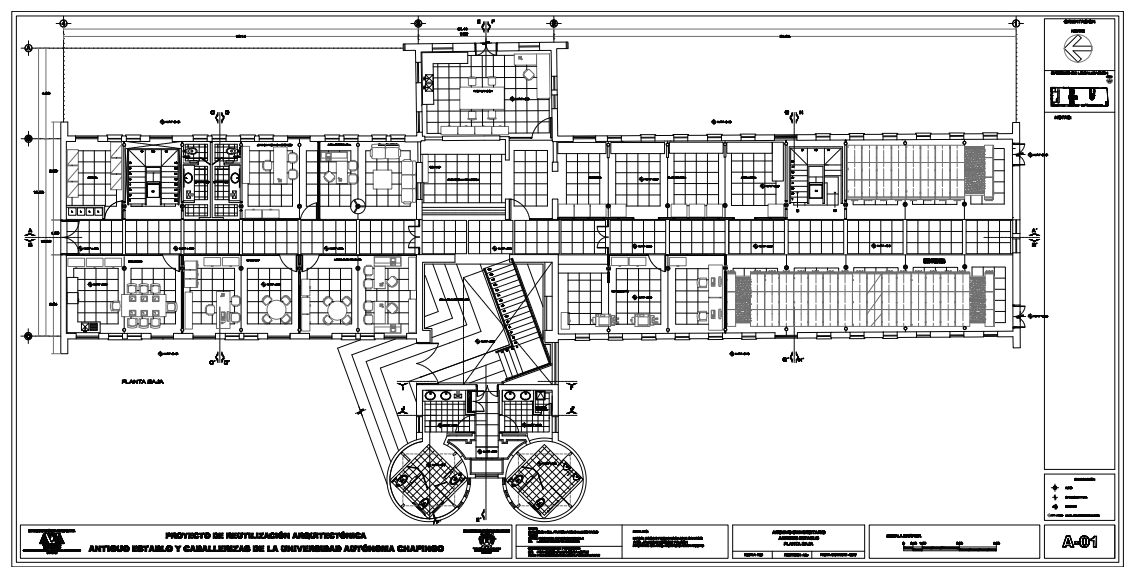

(a)

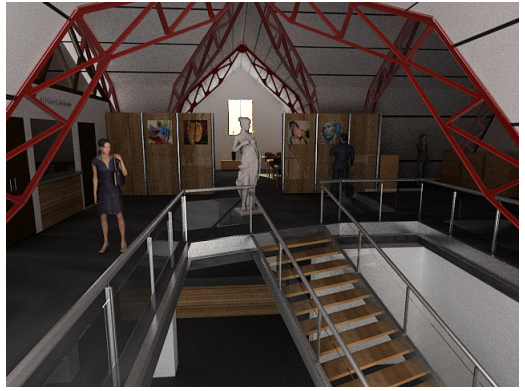

(b)

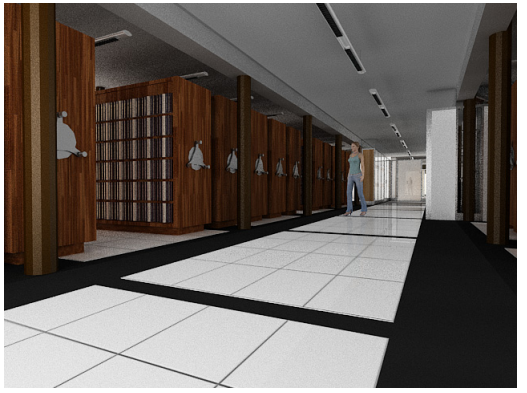

(c)

Figure 8: (a) The ground floor of the University Archives; (b) and (c) two interior views of the adaptive reuse project.

- $\quad$ The top floor also adapts the new use to the cross section plan. In the central part a double height space contains the main lobby with the stairways and leads to the consultation room. The North Wing, houses the historical 
archive, which also has a small temperature-controlled Chamber to keep photographs, negatives and documents that require a special temperature. The general file of the UA is located in the South Wing, where special mobile compactor shelving cabinets will be installed.

- The two round and triple-height silos are without doubt the dominant architectural elements of the old barn. It was decided to divide these storage spaces in three inner vertical floors in order to accommodate on the ground level both men and women bathrooms, the digital files and computer equipment on first floor and a storage space in the last section.

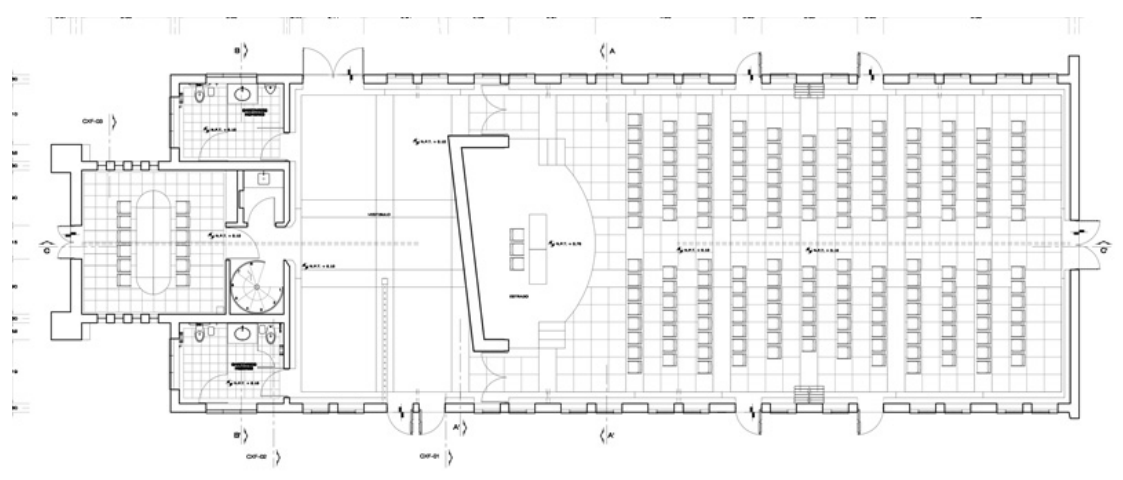

(a)

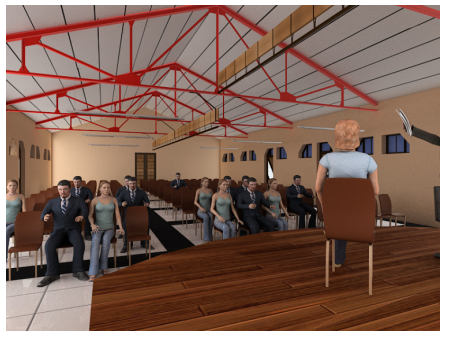

(b)

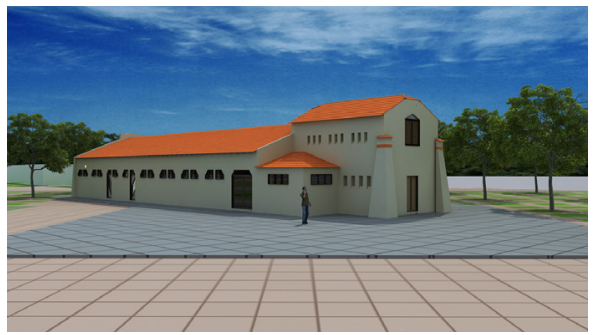

(c)

Figure 9: (a) The main layout of the multipurpose facilities in the former horse stables building; (b), (c) two views of the project; on the left, the main nave used as an auditorium; on the right, an outside view of the construction.

- The decision on how to distribute the spaces for the new UA also took into account the structural properties of the building, where the original design envisaged a significant load on the top floor, as a storage space, although the new files and documents to host will exceed the original weight consideration. Also, due to the age of the property, an intervention to improve and update the structural behavior was a must, to be able to meet 
the current requirements in structural and earthquake safety. In this sense the main structural upgrading will be in re-foundation, to broaden the contact base with the ground. Also the structural analysis indicated that the existing steel columns would be insufficient to carry the new loads. For these reasons, the building will be reinforced with isolated concrete foundations that support rows of new steel columns, one to replace the existing columns in the center, and a new row adjacent to the walls to ensure the stability of the buildings. The gambrel roof steal structures, which cover the top floor, were analyzed and their structural work complies with all safety requirements so only general maintenance and cleaning are needed.

- A fundamental criterion for the design of these facilities was to minimize any physical and ambience impact on the existing building. For this purpose all electrical, hydraulic and other infrastructure networks should be distributed mainly through floor space. On the ground level since refoundation would imply a major intervention, all tubing and ducts will be incorporated at that time. On the top floor a 'false' floor with a clearance of $25 \mathrm{~cm}$. was incorporated to accommodate all the required ductwork without damaging the original concrete slab, since it will keep its initial structural performance.

- The facades in general do not suffer major alterations, with the exception of the incorporation of a top floor that connects the silos with the central double-height lobby.

- $\quad$ Regarding the building of the horse stables, it will be used to support the AU dissemination activities. This construction has a very simple composition with two well differentiated sections. We sought to maintain its spatial features, especially the wide main nave. The latter will serve as a multipurpose space that can be subdivided with movable elements to adapt to different activities. Accordingly, a first permanent partition was included to define a main hall or distribution lobby from the multi-purpose space. In order to maintain the spatial continuity, at least partially, the dividing element is solid only up to a height of $3 \mathrm{~m}$. and has transparent glass at the top so the entire structure of the roof can be seen from both sides. The multifunctional space can be subdivided in turn by mobile screens to give different spatial formats: as a broad forum and exhibit space without divisions and as rooms for seminars when it is subdivided. A small meeting room is located on the ground floor of the central body. To the sides in two adjacent small rooms the restrooms were incorporated. Finally on the top floor of the central body, due to the poor accessibility, it was decided to use this room to allocate electrical and computer equipment, with restricted access.

\section{Conclusion}

The reuse of heritage architecture is not only a current alternative, but an increasingly important professional practice since it contributes to safeguard memory, strengthens the identity and refunctionalizes significant spaces, often 
already obsolete, not to mention its contribution to the conservation of the natural environment by increasing the constructions life cycle.

When approaching an intervention aimed at rescuing a pre-existing building, it is essential to have a double vision starting point: on the one hand it is necessary to know and learn its main characteristics, those that give the building its heritage value and, on the other hand, to consider from the beginning the possible new use it may have. Even when a property does not change its original use (to remain as a house or school), use changes, since needs vary in time, technology advances, trends are renewed, styles are imposed. In other words it is crucial that new uses or updated use of patrimonial spaces retain their main characteristics and elements; the new conditions must be compatible with the existing settings.

In the case of recovery of the livestock facilities of the UACH a fundamental premise was the recovery of the adjacent open spaces, because architecture must never be seen as an isolated object. Those recovered open areas will also serve to design services related to the new UA, as well as squares and gardens that will allow reintegrating part of the genius loci that this area once had.

The architectural reuse project for both buildings; cow barn and horse stables, aims to preserve their main functional, spatial and compositional characteristics. At the same time it provides new elements of contemporary design, clearly differentiated from the pre-existing ones, which are harmoniously integrated into the property. The projects it twofold: it conserves and contributes at the same time. Finally, it is important to highlight that the reuse of the built heritage is probably one of the best ways to ensure its conservation in the long run.

\section{Acknowledgements}

This reuse project, as well as all the information formerly presented, was developed under an inter-institutional cooperation agreement celebrated between the Chapingo Autonomous University and the Metropolitan Autonomous University Xochimilco Campus, through its Academic and Research faculty in Conservation and Reuse of Built Heritage group to which the three authors of this paper belong.

\section{References}

[1] Soria, F., Alfaro, F. \& Limones, C., Urban and architectural reuse of the former Chapingo Hacienda: sustainable criteria for the conservation of built heritage, in Structural Studies, Repairs and Maintenance of Heritage Architecture XII, WIT press, Southampton, 2011, pp. 173-184.

[2] Division for Historic Preservation and Vermont Housing and Conservation, Taking Care of Your Old Barn Historic Barn Types, Vermont, 1995, consulted at http://www.uvm.edu/ vhnet/hpres/publ/barnb/bbhbty.html, March 20, 2011.

[3] Auer, Michael J., The Preservation of Historic Barns, National Park services, consulted at http://www.nps.gov/history/hps/tps/briefs/brief20.htm, January 15, 2013. 